\title{
Role of sperm-surface glycoproteins in gamete recognition in two mouse species
}

\author{
H. Lambert
}

\begin{abstract}
Division of Reproductive Medicine, Department of Obstetrics and Gynecology, Suber House, School of Medicine, University of California, Davis, California 95616, U.S.A.
\end{abstract}

\begin{abstract}
Summary. In-vitro fertilization and sperm binding to the zona pellucida within and between Mus musculus (laboratory mouse) and Mus caroli (Asian wild field mouse) were examined. Maximum homologous sperm binding in $M$. musculus was $12 \cdot 3 \pm 0.3$ spermatozoa bound/egg and in $M$. caroli, $9 \cdot 2 \pm 0 \cdot 2$. In heterologous crosses, spermzona binding was significantly reduced ( $M$. musculus eggs with $M$. caroli spermatozoa, $1.9 \pm 0 \cdot 14 ; M$. caroli eggs with $M$. musculus spermatozoa, $5 \cdot 5 \pm 0 \cdot 2$ ). Homologous sperm-zona interaction was inhibited by different sugars in the two mouse species $(M$. caroli by $\alpha$-methyl mannose, $M$. musculus by sialic acid). The data suggest that gamete recognition is highly species specific and that hapten sugars play a significant role in sperm-zona binding.
\end{abstract}

\section{Introduction}

Current evidence suggests that species specificity in gamete interaction is determined by components on the surface of the sperm plasma membrane and that of the zona pellucida (Peterson, Russell, Bundman \& Freund, 1979, 1980). The membrane components involved in gamete recognition have been identified in several species. In the sea urchin (Strongylocentrotus purpuratus) (Glabe \& Vacquier, 1978; Glabe \& Lennarz, 1979) and guinea-pig (Huang, Ohzu \& Yanagimachi, 1982), lectin-like elements on the surface of the spermatozoon bind to glycoconjugates on the egg surface. Sperm-egg binding was inhibited by fucoiden, suggesting that there is a fucose-specific lectin on the spermatozoa.

In pigs and mice, glycoproteins on the surface of the spermatozoon and the egg are responsible for mediating binding, although it seems likely that the lectin-like element is present on the zona pellucida and ligand-like element is present on the sperm plasma membrane. Ligand-like elements were demonstrated on boar spermatozoa by the use of antiserum and univalent (Fab) antibody (Peterson et al., 1979, 1980). Sugar treatment of mouse (Chapman, Lambert \& Le, 1982; Lambert \& Chapman, 1982) and hamster (Ahuja, 1982) eggs inhibited fertilization, and glycosidase treatment of spermatozoa inhibited binding.

In this study, in-vitro fertilization and sperm binding to the zona pellucida within and between two species of mouse were examined to determine whether the efficiency of gamete interaction is lower or higher during sperm-zona recognition, and if so, whether this difference could be used to characterize specific components of the gamete recognition process in mammalian species.

The two mouse species used were Mus musculus (laboratory mouse) and Mus caroli (Asian wild field mouse), which do not interbreed. Attempts to produce interspecific hybrids using artificial insemination resulted in low frequencies $(<1 \%)$ of interspecific hybrids surviving to term between 
M. musculus females with $M$. caroli spermatozoa (West, Frels, Papaioannous, Karr \& Chapman, 1977). The genomes of these species are sufficiently compatible that adult hybrid mice can be produced, particularly in an interspecific chimaeric uterine environment.

\section{Materials and Methods}

Oocytes were obtained from superovulated inbred ICR/Ha (M. musculus) and Asian field ( $M$. caroli) mice (6-10 weeks old), given 4-8 i.u. PMSG (Sigma, St Louis, MO, U.S.A.) intraperitoneally followed $48-56 \mathrm{~h}$ later by 4-8 i.u. hCG (Sigma). Ova were collected from excised oviducts $15-16 \mathrm{~h}$ after hCG injection. Cumulus dispersal was accomplished by transferring egg masses to culture medium containing hyaluronidase ( $0 \cdot 1 \%$, Sigma Type I) for $10 \mathrm{~min}$. Adherent cumulus cells were removed by micropipetting. Ova were pooled and stored under oil until divided randomly into experimental and control groups.

Mouse sperm suspensions were prepared by transecting the excised cauda epididymidis of mature, sexually active males. After allowing for dispersal of spermatozoa in $10 \mathrm{ml}$ Medium BWW (Biggers, Whitten \& Whittingham, 1971) samples were washed 3 times in fresh Medium BWW (10 $\mathrm{ml})$ by centrifugation $(100 \mathrm{~g})$ for $5 \mathrm{~min}$. The last wash was stood for $10 \mathrm{~min}$ to allow viable spermatozoa from the pellet to swim into the supernatant. Sperm motility was subjectively evaluated throughout the investigation by examination under the microscope.

The culture medium for collection of oocytes was Brinster's culture medium (Gibco, N.Y., U.S.A.). Medium for sperm preincubation and gamete culture was Medium BWW or modified Tyrode's solution with $10 \mathrm{~mm}$-sodium lactate, $1.0 \mathrm{~mm}$-sodium pyruvate, $5.56 \mathrm{mM}$-glucose, and $10 \mathrm{mg}$ $\mathrm{BSA} / \mathrm{ml}$. All studies of capacitation and gamete interaction were carried out under sterile mineral oil at $37^{\circ} \mathrm{C}, 100 \%$ humidity, and $5 \% \mathrm{CO}_{2}$, in air.

Sperm sample preparations $\left(10^{5}\right.$ spermatozoa/ml $)$ were preincubated in Medium BWW at $37^{\circ} \mathrm{C}$ ( $90 \mathrm{~min}$ for M. musculus and $120 \mathrm{~min}$ for $M$. caroli), then combined with eggs for $5 \mathrm{~min}$. The spermegg samples were then centrifuged at $100 \mathrm{~g}$ for $90 \mathrm{sec}$ through a $1.8 \%$ and $2.25 \%$ discontinuous dextran gradient with glutaraldehyde in the lower solution ('stop-fix' technique) (Saling, Storey \& Wolf, 1978). Eggs were recovered from the gradient and the number of spermatozoa bound per egg was calculated from visual counts of the total number of bound spermatozoa and the total number of eggs in the sample. In-vitro fertilization experiments were done as described above except that the 'stop-fix' gradient did not contain glutaraldehyde. Eggs were recovered from the gradient tubes, incubated for $2 \mathrm{~h}$, and assayed for swollen sperm heads. All egg numbers are the result of pooling data from several experiments ( 20 eggs per experiment).

The inhibition of sperm-egg binding by different sugars (Sigma) was also examined because this interaction is believed to be a sugar-lectin mediated process. Cumulus-free eggs were incubated with sialic acid, fucose, galactose, $N$-acetylglucosamine, $\alpha$-methyl mannose or glucose at concentrations of $0.1 \mathrm{mM}$ to $50.0 \mathrm{mM}$ for $30 \mathrm{~min}$, washed, combined with spermatozoa that had been preincubated in Medium BWW for $90 \mathrm{~min}$, and the number of spermatozoa bound per egg determined as described above. In other experiments, capacitated spermatozoa $\left(1 \times 10^{5} / \mathrm{ml}\right)$ were exposed to the same sugars under the same conditions and the numbers of spermatozoa bound per egg were determined.

The effect of mannosidase and neuraminidase treatment on sperm-egg binding was also examined. Spermatozoa of both species were preincubated and then treated with neuraminidase (25 i.u./ml) or mannosidase ( 25 i.u. $/ \mathrm{ml})$ for $30 \mathrm{~min}$. Sperm samples were then thoroughly washed and incubated with eggs for $30 \mathrm{~min}$. Samples were put through the 'stop-fix' gradient and assayed for binding. Similarly, cumulus-free eggs from both species were treated with the glycosidases for $30 \mathrm{~min}$, rinsed thoroughly and incubated with capacitated spermatozoa. The eggs were then processed as above.

The effect of the human sialylated protein, orosomucoid (Miles Laboratory, IN, U.S.A.) was similarly investigated. 


\section{Results}

The concentration of spermatozoa required to give maximum sperm binding was $1 \times 10^{5} / \mathrm{ml}$. The binding rates for various combinations of eggs and spermatozoa are given in Table 1. Sperm-zona binding was significantly reduced in the heterologous crosses. Frequencies of fertilization in heterologous crosses were also lower (Table 1). When eggs were preincubated with various sugars, then assayed for sperm binding, sialic acid was the most effective inhibitor of binding for $M$. musculus eggs and spermatozoa, with $50 \%$ inhibition occurring with $<0.1 \mathrm{~mm}$-sialic acid; by contrast, more than 100-fold higher concentration of sialic acid was required to achieve $50 \%$ inhibition of binding with $M$. caroli eggs and spermatozoa (Text-fig. 1). $\alpha$-Methylmannose was the most effective inhibitor of binding in $M$. caroli with $50 \%$ inhibition occurring at $0.1 \mathrm{mM}$. However, more than 70 -fold higher concentration of $\alpha$-methylmannose was required to achieve $50 \%$ inhibition of binding in $M$. musculus (Text-fig. 1). No significant inhibition of sperm binding was observed with fucose, galactose, $\mathrm{N}$-acetylglucosamine, or glucose, in concentrations ranging from $0 \cdot 1$ to $50 \mathrm{~mm}$.

Capacitated $M$. musculus spermatozoa did not bind to $(0.4 \pm 1 \cdot 2$ spermatozoa/egg, 67 eggs) or fertilize $(9 \%, 6 / 62$ eggs) after neuraminidase treatment, but this treatment had no effect on $M$. caroli spermatozoa. However, mannosidase did eliminate sperm binding $(0 \cdot 2 \pm 0 \cdot 3$ spermatozoa/egg, 41 eggs) and fertilization ( $2 \%, 1 / 41$ eggs) in $M$. caroli.

Sperm-zona binding in $M$. musculus was also inhibited when eggs were pretreated with orosomucoid (Text-fig. 2) but similar levels of inhibition in $M$. caroli required approximately 100 fold higher concentrations. Orosomucoid inhibited sperm-zona binding by $45 \%$ in $M$. musculus at $1.0 \mu \mathrm{g} / \mathrm{ml}$, whereas no effect was observed in $M$. caroli at this dose (Text-fig. 2).

Table 1. Sperm binding rates and in-vitro fertilization results for $M$. musculus and $M$. caroli eggs and spermatozoa

\begin{tabular}{llcc}
\hline \multicolumn{1}{c}{ Female } & \multicolumn{1}{c}{ Male } & Binding (spermatozoa/egg) & Fertilization (\%) \\
\hline$M$. musculus & $M$. musculus & $12 \cdot 3 \pm 0 \cdot 3$ & $182 / 211(86)$ \\
$M$. caroli & $M$. caroli & $9 \cdot 2 \pm 0 \cdot 2$ & $88 / 139(63)$ \\
$M$. musculus & $M$. caroli & $1.9 \pm 0.14$ & $12 / 149(8)$ \\
$M$. caroli & $M$. musculus & $5 \cdot 5 \pm 0 \cdot 2$ & $46 / 130(35)$ \\
\hline
\end{tabular}

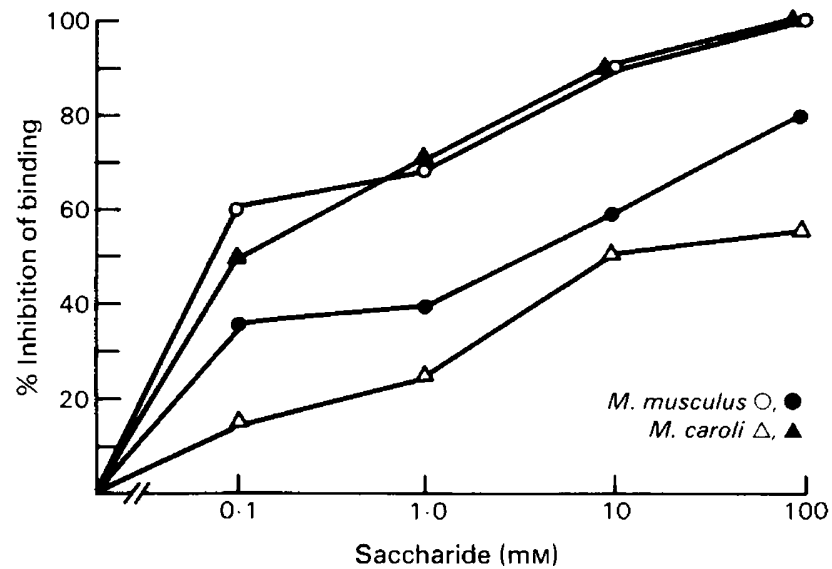

Text-fig. 1. Inhibition of sperm-egg binding by sugars. Eggs were incubated with various concentrations of sialic acid $(O, \Delta)$ and $\alpha$-methyl mannose $(\boldsymbol{O}, \boldsymbol{\Delta})$ for $30 \mathrm{~min}$, washed and combined with capacitated spermatozoa. 


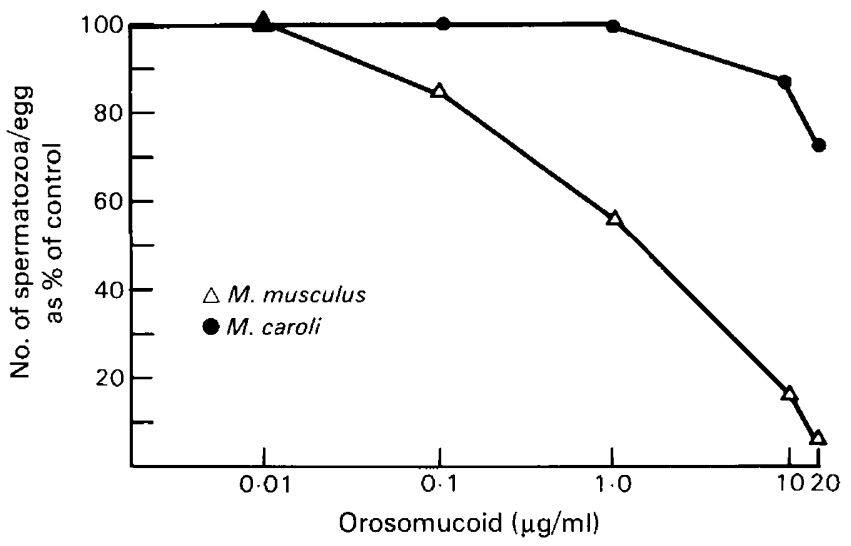

Text-fig. 2. The inhibition of sperm-egg binding in mice by orosomucoid. Eggs were incubated for $30 \mathrm{~min}$, washed and combined with preincubated spermatozoa $\left(1 \times 10^{5} \mathrm{ml}\right)$.

\section{Discussion}

The data presented in this paper clearly demonstrate that the mechanism of the binding of spermatozoa to the surface of the zona pellucida during the fertilization process has a pronounced species specificity. These results are consistent with the model that sperm plasma membrane glycoproteins interact with lectin-like elements on the zona pellucida (Ahuja, 1982). The differences in plasma membrane glycoproteins could be used to explain the differences observed in sperm-zona recognition and contribute to the low frequency of interspecific fertilization between these two mouse species. Further characterization of sperm plasma membrane glycoproteins will help to determine the importance of differences in the terminal sugar residues in gamete recognition. It will also be necessary to determine whether this is a property of a specific glycoprotein on the plasma membrane or of protein glycosylations which are present on several components of the membrane.

\section{References}

Ahuja, K.K. (1982) Fertilization studies in the hamster: the role of cell surface carbohydrates. Expl Cell Res. 140, 353-362.

Biggers, J.D., Whitten, W.K. \& Whittingham, D.G. (1971) The culture of mouse embryos in vitro. In Methods in Mammalian Embryology, pp. 86-116. Ed. J. C. Daniel, Jr. W. H. Freeman \& Co., San Francisco.

Chapman, V.C., Lambert, H. \& Le, A.V. (1982) Analysis of the sperm-zona binding complex in the mouse. Anat. Rec. 202, 29, Abstr.

Glabe, C.G. \& Lennarz, W.J. (1979) Species-specific sperm adhesion in sea urchins: a quantitative investigation of binding mediated egg agglutination. $J$. Cell Biol. 83, 595-604.

Glabe, C.G. \& Vacquier, V.D. (1978) Egg surface glycoprotein receptor for sea urchin sperm binding. Proc. natn. Acad. Sci. U.S.A. 75, 881-885.

Huang, T., Ohzu, E. \& Yanagimachi, R. (1982) Evidence suggesting that $\mathrm{L}$-fucose is part of a recognition signal for sperm-zona pellucida attachment in mammals. Gamete Res. 5, 355-362.
Lambert, H. \& Chapman, V.M. (1982) Analysis of binding and fertilization differences in two species of mouse. Biol. Reprod. 26, 85, Abstr.

Peterson, R.N., Russell, L., Bundman, D. \& Freund, M. (1979) Direct evidence for boar sperm plasma membrane receptors for the zona pellucida. $J$. Cell Biol. 83, 700, Abstr.

Peterson, R.N., Russell, L., Bundman, D. \& Freund, M. (1980) Sperm-egg interaction: direct evidence for boar plasma membrane receptors for porcine zona pellucida. Science, N.Y. 207, 73-74.

Saling, P.M., Storey, B.T. \& Wolf, D.P. (1978) Calcium dependent binding of mouse epididymal spermatozoa to the zona pellucida. Devl Biol. 65, 515-525.

West, J.D., Frels, I.W., Papaioannous, V.E., Karr, J.P. \& Chapman, V.M. (1977) Development of interspecific hybrids of Mus. J. Embryol. exp. Morph. 41, 233-243. 